\title{
A Matemática no Pequeno Luterano na década de 1940
}

\author{
The Mathematics in the Little Lutheran in the 1940s
}

\author{
Malcus Cassiano Kuhn*a; Arno Bayer ${ }^{\mathrm{b}}$ \\ ${ }^{a}$ Instituto Federal de Educação, Ciência e Tecnologia Sul-rio-grandese. RS, Brasil.

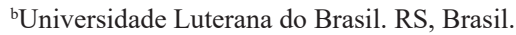 \\ *E-mail: malcuskuhn@ifsul.edu.br
}

\begin{abstract}
Resumo
O artigo é recorte de uma pesquisa sobre a Matemática nas escolas paroquiais luteranas gaúchas do século XX e tem por objetivo analisar as edições do periódico O Pequeno Luterano, editadas na década de 1940, com ênfase para o discurso matemático veiculado no mesmo, por meio dos textos, imagens e enunciados, suas intencionalidades e abordagens. O periódico foi editado para o público infantil pela Igreja Evangélica Luterana do Brasil, por meio da Casa Publicadora Concórdia de Porto Alegre, no período de 1939 a 1966. Com abordagem qualitativa e análise de fontes documentais, a pesquisa possui aporte metodológico na pesquisa histórica e no conceito de cultura escolar, para análise das 86 edições do Pequeno Luterano (1939-1949). O principal objetivo dos editores do periódico era, de forma lúdica, inserir as crianças na prática religiosa luterana por meio de textos, histórias, informações e curiosidades de cunho moral e religioso e de formação geral. Foi usado no ensino das diferentes áreas do conhecimento nas escolas paroquiais luteranas gaúchas do século passado. Os editores propunham desafios matemáticos para desenvolver o raciocínio lógico das crianças e valorizavam as habilidades concretas e abstratas do aprendizado matemático através do cálculo escrito e mental, em forma de atividades lúdicas. Cálculos foram relacionados com a biografia de matemáticos e os conhecimentos matemáticos integrados a histórias de cunho moral e religioso, com o propósito de manter as crianças inseridas na prática religiosa luterana.

Palavras-chave: História da Educação Matemática. Escolas Paroquiais Luteranas Gaúchas. Periódico Infantil.
\end{abstract}

\begin{abstract}
The article it's a clipping of a research about the Mathematics in the gaucho Lutheran parochial schools of the $20^{\text {th }}$ century and has aims analyze the editions of the journal The Little Lutheran, edited in the 1940s, with emphasis on the mathematical discourse conveyed in it, through texts, images and statements, their intentions and approaches. The journal was edited for the infantile public by the Evangelical Lutheran Church of Brazil, through of the Concordia Publishing House of Porto Alegre, in the period of 1939 to 1966. With qualitative approach and analysis of documentary sources, the research possui methodological approach on history research and on concept of school culture, to analised of the 86 editions of the journal Little Lutheran (1939-1949). The principale aims of the editors of the journal was, de forma lúdica, insert the children in the Lutheran religious practice through of texts, stories, information and curiosities of nature moral and religious and of general education. Was used, complementarily, in the teaching of the different areas of knowledge in the gaucho Lutheran parochial schools of the past century. The editors proposed mathematical challenges to develop the logical reasoning of the children and valued the concrete and abstract skills of the mathematical learning through of the written and mental calculation, in form of playful activities. Calculations were related to the biography of mathematicians and the mathematical knowledges integrated with stories of moral nature and religious, with the purpose of keeping the children inserted in Lutheran religious practice.
\end{abstract}

Keywords: History of Mathematics Education. Gaucho Lutheran Parochial Schools. Children's Journal.

\section{Introdução}

O tema desta investigação se insere na História da Educação Matemática no Rio Grande do Sul - RS, no âmbito das Escolas Evangélicas Luteranas do Brasil. Tratase de um estudo que contempla os imigrantes alemães e seus descendentes no estado gaúcho e tem como questão norteadora a Matemática praticada nas escolas paroquiais luteranas gaúchas do século XX.

Este artigo tem por objetivo discutir a Matemática presente no Pequeno Luterano, durante a década de $1940^{1}$, com ênfase para o discurso matemático veiculado no periódico, por meio dos textos, imagens e enunciados, suas intencionalidades e abordagens. É um recorte da tese "O ensino da Matemática nas Escolas Evangélicas Luteranas do Rio Grande do Sul durante a primeira metade do século XX”, aprofundado durante o estágio Pós-doutoral, com investigação da "Matemática nas escolas paroquiais luteranas do Rio Grande do Sul”, junto ao Programa de Pós-Graduação em Ensino de Ciências e Matemática (PPGECIM) da Universidade Luterana do Brasil (ULBRA).

O Pequeno Luterano foi produzido pela Igreja Evangélica Luterana do Brasil - IELB - para o público infantil e

1 Esse recorte compreende os 10 primeiros anos de edição do periódico e os reflexos iniciais do processo de nacionalização do ensino, o qual foi regido por uma série de decretos dos governos federal e estadual, emitidos no final da década de 1930, que disciplinaram a licença de professores e o material didático a ser usado nas escolas, tornaram o idioma nacional obrigatório (português) para a instrução e prescreveram a formação cívica brasileira. 
publicado pela Casa Publicadora Concórdia ${ }^{2}$, de Porto Alegre. Teve sua $1^{\text {a }}$ edição publicada em agosto/setembro de 1939. Com publicações mensais, bimestrais ou quadrimestrais, o periódico foi usado de forma complementar, por professores paroquiais, no ensino das diferentes áreas do conhecimento nas escolas paroquiais luteranas gaúchas do século passado, com 217 edições, totalizando 2061 páginas. O periódico foi editado até junho de 1966 e, posteriormente, passou a circular como encarte de uma página no periódico Mensageiro Luterano.

Como a temática investigada se insere na História da Educação Matemática no RS, busca-se na pesquisa histórica e no conceito de cultura escolar, o suporte para discussão. Para investigar $O$ Pequeno Luterano se realizaram visitas ao Instituto Histórico da IELB, localizado em Porto Alegre, onde se encontram as edições do mesmo ${ }^{3}$. Ao pesquisar minuciosamente cada edição, compilaram-se os excertos relacionados à Matemática para posterior análise à luz do referencial teórico-metodológico.

No estudo do Pequeno Luterano, além do referencial teórico-metodológico, apresentam-se uma breve caracterização das escolas paroquiais luteranas gaúchas do século passado e uma discussão dos conhecimentos matemáticos abordados no periódico na década de 1940.

\section{O Aporte Teórico-Metodológico da Investigação}

Como a temática investigada se insere na História da Educação Matemática no RS, busca-se na pesquisa histórica e no conceito de cultura escolar, o suporte para discussão. De acordo com Prost (2008), os fatos históricos são constituídos a partir de traços, de rastros deixados no presente pelo passado. Assim, o trabalho do historiador consiste em efetuar um trabalho sobre esses traços para construir os fatos. Desse modo, um fato não é outra coisa que o resultado de uma elaboração, de um raciocínio, a partir das marcas do passado. $\mathrm{O}$ autor considera o trajeto da produção histórica como sendo um interesse de pesquisa, a formulação de questões históricas legítimas, um trabalho com os documentos, como as edições do periódico Pequeno Luterano, e a construção de um discurso que seja aceito pela comunidade.

Certeau (1982) define o fazer história, no sentido de pensar a história como uma produção. Para o autor, a história, como uma produção escrita, tem a tripla tarefa de convocar o passado que já não está em um discurso presente, mostrar as competências do historiador (dono das fontes) e convencer o leitor. Desta forma, a prática histórica é prática científica enquanto a mesma inclui a construção de objetos de pesquisa, o uso de uma operação específica de trabalho e um processo de validação dos resultados obtidos, por uma comunidade.

O trabalho do historiador, de acordo com Certeau (1982), não se limita a produzir documentos, textos em uma nova linguagem. Isso ocorre porque no seu fazer pesquisa há um diálogo constante do presente com o passado, e o produto desse diálogo consiste na transformação de objetos naturais em cultura. Julia (2001, p.10) define a cultura escolar como:

Um conjunto de normas que estabelecem conhecimentos a ensinar e condutas a inculcar, e um conjunto de práticas que permitem a transmissão desses conhecimentos e a incorporação desses comportamentos; normas e práticas coordenadas a finalidades que podem variar segundo às épocas.

Então, o estudo da cultura escolar instiga a busca pelas normas e finalidades que regem a escola, a avaliação do papel desempenhado pelo professor e a análise dos conteúdos ensinados e das práticas escolares. Chervel (1990) considera importante o estudo da cultura escolar para a compreensão dos elementos que participam da produção/elaboração/ constituição dos saberes escolares e, em particular, da matemática escolar e sua história.

Conforme Valente (2007), há uma infinidade de materiais que junto com os livros didáticos podem permitir compor um quadro da Educação Matemática de outros tempos. Para o autor, pensar os saberes escolares como elementos da cultura escolar, realizar o estudo histórico da Matemática escolar, exige que se devam considerar os produtos dessa cultura do ensino de Matemática, que deixaram traços que permitem o seu estudo, como o periódico Pequeno Luterano, principal fonte documental desta investigação. Antes, porém, é preciso fazer uma breve abordagem sobre as escolas paroquiais luteranas gaúchas do século XX.

\section{As Escolas Paroquiais Luteranas Gaúchas do Século XX}

No Brasil, os princípios cristãos de Lutero, se fizeram presentes, a partir de 1824, com a vinda das ideias luteranas através dos primeiros imigrantes alemães. Lutero traçou princípios gerais sobre a educação, os quais se fundamentaram na Bíblia. "A premissa fundamental é de que a Bíblia ensina que Deus criou o universo e mantém, governa e sustenta toda a criação, sendo o homem a obra máxima da criação". (Lemke, 2001, p. 34).

Nesta perspectiva luterana, o Sínodo Evangélico Luterano Alemão de Missouri ${ }^{4}$, atualmente IELB, começou sua missão nas colônias alemãs do RS, em 1900, fundando congregações religiosas e escolas paroquiais. Para o Sínodo de Missouri

2 Fundada em 1923, atuava na edição de livros e periódicos relacionados à literatura religiosa e escolar da IELB. Foi a primeira e a única editora da IELB, existente até os dias atuais. Antes de sua fundação, os livros e os periódicos eram impressos pela Concordia Publishing House, nos Estados Unidos, e enviados ao Brasil.

3 No Instituto Histórico da IELB, não foram encontradas edições do periódico ou referências sobre sua publicação no período de setembro a dezembro de 1953. Em sua tese, Weiduschadt (2012), também destaca a não localização de edições neste mesmo período.

4 Em 1847, um grupo de imigrantes luteranos alemães da Saxônia fundou no estado de Missouri (Estados Unidos), o Sínodo Evangélico Luterano Alemão de Missouri, Ohio e Outros Estados, atualmente Igreja Luterana - Sínodo de Missouri. 
era necessário consolidar um campo religioso e fortalecê-lo investindo na escola, influenciando o campo familiar dos seus possíveis fiéis. Por isso, os missourianos não somente cuidaram da formação de pastores como também de professores que atuassem de acordo com a filosofia educacional missouriana para que as escolas paroquiais atingissem seus objetivos como agência missionária e de educação geral.

Conforme Kuhn \& Bayer (2017b), as escolas paroquiais luteranas gaúchas estavam inseridas num projeto missionário e comunitário que buscava ensinar a língua materna, a Matemática, valores culturais, sociais e, principalmente, religiosos. Tais escolas:

Tinham uma responsabilidade para com a comunidade no sentido de, junto e com ela, promover o crescimento e o desenvolvimento pessoal de todos que a compunham, focando a cidadania. Se a escola formasse o ser humano com postura ética e moral exemplar, este poderia promover transformações sólidas em seu contexto social e seria um verdadeiro colaborador na seara de Deus e para o governo do mundo. (Kuhn \& Bayer, 2017b, p.132).

As escolas paroquiais luteranas gaúchas, geralmente, eram constituídas por classes multisseriadas, mantidas pela comunidade escolar/paroquial e subvencionadas pelo Sínodo de Missouri para pagamento do salário do professor/pastor. Como havia poucos materiais didáticos nestas escolas, o ensino acontecia na base da recitação e da memorização. Os professores paroquiais eram formados pelo Seminário Concórdia ${ }^{5}$, de acordo com os princípios morais e religiosos da Igreja Luterana. A prática pedagógica deveria levar em consideração a realidade dos alunos, para que, futuramente, os mesmos se engajassem de forma ativa nas estruturas comunitárias. (Kuhn \& Bayer, 2017b).

Os egressos das escolas paroquiais luteranas gaúchas tinham maior conhecimento da Bíblia e uma formação consistente de crenças e valores cristãos tradicionais que enfatizavam a importância do relacionamento com Deus e com outras pessoas. Tinha-se a preocupação pedagógica para que a espiritualidade fosse vivida no dia a dia e não se reduzisse a ritos religiosos. (Kuhn \& Bayer, 2017b).

O Sínodo de Missouri também direcionava sua atenção para os materiais didáticos usados nas escolas paroquiais, pois este material era escasso e a dificuldade era grande em manter um ensino planificado e organizado. De acordo com Weiduschadt (2007, p. 41), "os livros usados nas escolas paroquiais e utilizados pelos alunos foram produzidos pelas instituições religiosas com objetivo de formar e moldar as condutas e as práticas ao fazer a escolarização das comunidades". Assim, por meio dos livros didáticos e dos periódicos, como o periódico Pequeno Luterano que é abordado na seção seguinte, as escolas paroquiais luteranas gaúchas conseguiram desenvolver uma educação integral cristã em todas as disciplinas. Nessas escolas, conforme Lemke (2001, p. 80), “o ensino da palavra de Deus, através da Bíblia, ficava em primeiro lugar, e as demais disciplinas não eram menosprezadas, mas complementavam a educação para servir no mundo".

\section{O Periódico O Pequeno Luterano}

O Pequeno Luterano foi produzido pela IELB para as escolas frequentadas por crianças luteranas, visando à formação do futuro fiel adulto (Weiduschadt, 2012). Teve sua primeira edição publicada em agosto/setembro de 1939. Editado em português, devido ao processo de nacionalização do ensino, em curso no país, O Pequeno Luterano substituiu o periódico Evangelisch-Lutherisches Kinderblatt für Südamerika (Jornal para crianças da Igreja Evangélica Luterana da América do Sul), editado pela IELB no período de dezembro de 1930 a junho/julho de 1939, em alemão.

A redação do periódico Pequeno Luterano foi realizada por pastores e/ou professores paroquiais que se dispunham a redigir ou adaptar os textos de forma voluntária, ou seja, não eram remunerados para esta função. Estes procuravam divulgar a doutrina luterana através de uma educação religiosa e escolar. $\mathrm{O}$ diretor geral do periódico, durante os seus quase 27 anos de circulação, foi Carlos Henrique Warth ${ }^{6}$. Os redatores do periódico nos seus primeiros 10 anos foram: Louis C. Rehefeldt ${ }^{7}$ (outubro de 1939 até setembro de 1940), Walter Hesse ${ }^{8}$ (outubro de 1939 até novembro de 1942), J. A. Schmidt $^{9}$ (dezembro de 1942 até novembro de 1945), Gastão Tomé ${ }^{10}$ (dezembro de 1945 até junho de 1946), Paulo Fietz $^{11}$ (julho de 1946 até dezembro de 1949). Esse período inicial do periódico foi turbulento, com trocas constantes de redatores, em função da pressão do Estado Novo em relação aos pastores/professores que não eram nascidos no Brasil.

Os redatores mantinham contato com os leitores, liam as cartas e organizavam o conteúdo do periódico, mas não tinham dedicação exclusiva como redatores. Em geral, acumulavam a função com o exercício do magistério e do pastorado. "Histórias bíblicas eram resumidas e, para cada uma delas, o redator apresentava uma mensagem, alertando o pequeno leitor, se ele estaria seguindo as indicações e

5 Instituto pedagógico-teológico que atuou na formação de pastores e de professores paroquiais para IELB no RS.

6 Nasceu no Brasil, foi pastor e redator de outros periódicos como Jovem Luterano e Lutherkalender. Além de cronista e estatístico da igreja, ocupou cargos administrativos, também na igreja. (Warth, 1979).

7 Nasceu nos Estados Unidos, foi diretor do Seminário Concórdia e redator do Mensageiro Luterano e Lar Cristão. Também ocupou cargos administrativos na igreja. (Warth, 1979).

8 Nasceu na Alemanha, formou-se no Seminário Concórdia em 1941. Foi redator do periódico ao mesmo tempo em que ocupou a função de pastor em Barros Cassal/RS. (Warth, 1979).

9 Formou-se como professor no Seminário Concórdia em 1919. Foi conselheiro escolar nos primórdios da fundação da igreja. (Warth, 1979).

10 Formou-se como professor no Seminário Concórdia em 1933. Trabalhou no Seminário Concórdia no período de 1944-1968. (Warth, 1979).

11 Formou-se como professor no Seminário Concórdia em 1945. (Warth, 1979). 
exortações da igreja" (Weiduschadt, 2012, p. 65). A edição e a publicação do periódico ficavam por conta da Casa Publicadora Concórdia. As cartas enviadas pelas crianças e por representantes de escolas paroquiais eram encaminhadas para a Casa Publicadora Concórdia, localizada em Porto Alegre, e repassadas aos redatores.

O Pequeno Luterano foi usado nas escolas paroquiais como veículo informativo, educativo e doutrinário, funcionando também como entretenimento para o público infantil. O periódico continha leituras sobre o ensino da Bíblia, do catecismo, da vida de Lutero. Ainda havia textos em formas de histórias que tratavam de assuntos sobre as noções de higiene e de comportamento moral, ao mesmo tempo, apresentando brincadeiras, como charadas e palavras cruzadas sobre textos e conhecimentos bíblicos. (Weiduschadt, 2012, p. 65-66).

As atividades lúdicas envolviam aspectos religiosos na sua centralidade, ou seja, mesmo em charadas, adivinhações e palavras cruzadas, o direcionamento religioso era valorizado. O público infantil valorizava e mantinha a assinatura do periódico, basicamente, devido aos temas de entretenimento, ilustrativos e publicitários. Weiduschadt (2012, p.93), acrescenta que "o aprendizado das crianças seria através de uma leitura controlada e doutrinária do periódico. A preocupação lúdica era um meio, o fim deveria estar na absorção da doutrina e na conduta de práticas relacionadas à igreja”. Dessa forma, o propósito do periódico em circular no meio escolar, apresentando conhecimento geral e ideológico, buscava interlocução entre os leitores através das escolas: primeiro as paroquiais e, após a década de 1960, as escolas dominicais.

Os preceitos conduta das crianças e aplicação da história eram voltados a orientar a projeção de futuro na formação dos leitores. Ao dirigir-se ao leitor, desejava-se formar o aluno e futuro cidadão/fiel imbricados no mesmo projeto, envolvendo escola, pátria e igreja. (Weiduschadt, 2012, p. 258).

A Figura 1 traz um fragmento da primeira edição do periódico Pequeno Luterano, mostrando informações de identificação do mesmo:

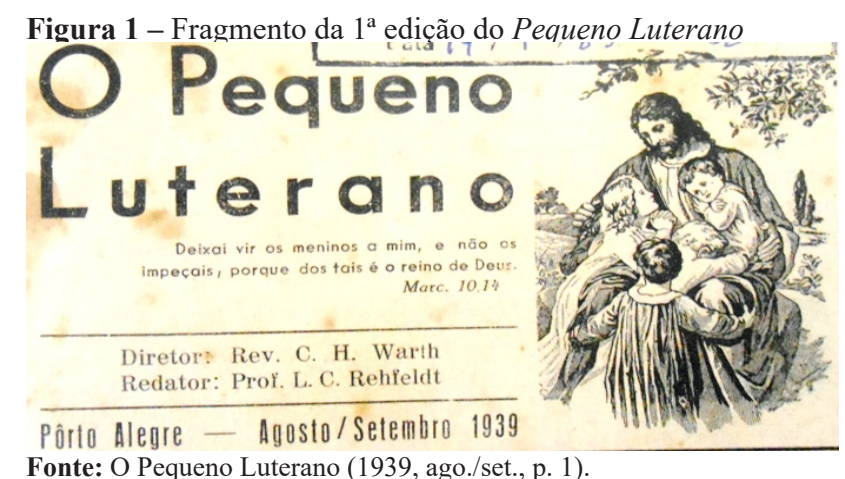

Além do título do periódico, O Pequeno Luterano, está escrito o local da edição, Porto Alegre, e o período, agosto/ setembro de 1939. Ainda se observam os nomes do diretor do periódico, Rev. C. H. Warth (diretor do Seminário Concórdia, na época), e o seu redator, Prof. L. C. Rehefeldt, professor do Seminário Concórdia, neste período. Também se observam uma passagem bíblica e uma imagem de Jesus acolhendo as crianças, a qual tem uma relação direta com um dos princípios luteranos de que a salvação de todos os homens se dá pela fé em Jesus Cristo (Lemke, 2001). Ressalta-se que houve variação na forma de apresentação inicial das edições do periódico, mas seu conteúdo sempre primou pelos princípios morais e educacionais idealizados pela IELB.

O Pequeno Luterano tinha como principal objetivo inserir as crianças na prática religiosa luterana por meio de textos, histórias, informações e curiosidades de cunho moral e religioso e de formação geral. Os editores usaram a estratégia de elaborar um periódico lúdico, com linguagem e imagens voltadas ao público infantil. Nas edições do periódico também havia um chamamento para pais, pastores e professores paroquiais incentivarem as crianças para a leitura do mesmo.

A redação previa que a ajuda de professores e pastores que lidavam diretamente com as crianças era fundamental para o estímulo da leitura. Se as crianças fossem convencidas da importância da leitura do periódico, os pais poderiam se sensibilizar em pagar o periódico. (Weiduschadt, 2012, p. 262).

A estratégia dos editores de receber cartas dos seus leitores, especialmente de alunos das escolas paroquiais, com depoimentos e respostas das charadas e desafios propostos no periódico, além dos relatos dos professores com informações sobre as escolas paroquiais luteranas e o número de alunos, contribuiu para circulação e inserção do Pequeno Luterano entre o público infantil. Isto foi reforçado pelo uso do periódico pelos professores paroquiais, de forma complementar, no ensino de diferentes conteúdos.

O Quadro 1 reúne informações gerais sobre as edições do Pequeno Luterano, nos seus primeiros 10 anos de edição:

Quadro 1 - Edições do Pequeno Luterano: década de 1940

\begin{tabular}{|c|c|c|c|}
\hline Ano & \multicolumn{2}{|l|}{ Edições } & $\begin{array}{l}\text { Total de } \\
\text { Páginas }\end{array}$ \\
\hline $\begin{array}{c}1- \\
1939 / 1940 \\
\end{array}$ & \multicolumn{2}{|c|}{$\begin{array}{c}7 \text { edições mensais e } 5 \text { edições } \\
\text { bimestrais }\end{array}$} & 68 \\
\hline $2-1941$ & \multicolumn{2}{|c|}{$\begin{array}{c}8 \text { edições mensais e } 2 \text { edições } \\
\text { bimestrais }\end{array}$} & 48 \\
\hline $3-1942$ & \multicolumn{2}{|c|}{$\begin{array}{l}10 \text { edições mensais e } 1 \text { edição } \\
\text { bimestral }\end{array}$} & 48 \\
\hline $4-1943$ & \multicolumn{2}{|c|}{$\begin{array}{c}6 \text { edições mensais e } 3 \text { edições } \\
\text { bimestrais }\end{array}$} & 48 \\
\hline $5-1944$ & \multicolumn{2}{|c|}{$\begin{array}{c}10 \text { edições mensais e } 1 \text { edição } \\
\text { bimestral }\end{array}$} & 48 \\
\hline $6-1945$ & \multicolumn{2}{|c|}{$\begin{array}{c}2 \text { edições bimestrais e } 2 \text { edições } \\
\text { quadrimestrais }\end{array}$} & 48 \\
\hline $7-1946$ & \multicolumn{2}{|c|}{$\begin{array}{l}4 \text { edições bimestrais e } 1 \text { edição } \\
\text { quadrimestral }\end{array}$} & 48 \\
\hline $8-1947$ & \multicolumn{2}{|c|}{$\begin{array}{c}6 \text { edições mensais e } 3 \text { edições } \\
\text { bimestrais }\end{array}$} & 48 \\
\hline $9-1948$ & \multicolumn{2}{|c|}{$\begin{array}{c}2 \text { edições mensais e } 5 \text { edições } \\
\text { bimestrais }\end{array}$} & 48 \\
\hline $10-1949$ & \multicolumn{2}{|c|}{$\begin{array}{c}4 \text { edições mensais e } 4 \text { edições } \\
\text { bimestrais }\end{array}$} & 52 \\
\hline Total & $\begin{array}{c}53 \text { edições mensais } \\
30 \text { edições bimestrais } \\
3 \text { edições quadrimestrais }\end{array}$ & $\begin{array}{c}86 \\
\text { edições }\end{array}$ & 504 \\
\hline
\end{tabular}

Fonte: O Pequeno Luterano (1939-1949). 
Observa-se no Quadro 1 que O Pequeno Luterano foi editado 86 vezes em seus primeiros 10 anos de circulação, sendo 53 edições mensais, 30 bimestrais e 3 edições quadrimestrais. O periódico geralmente era mensal, mas muitas edições circulavam bimestralmente, especialmente, nos meses de janeiro/fevereiro, período das férias escolares. Em momentos de crise, o periódico apresentava menor circulação. Especificamente em 1945-1946, em todo ano são publicadas 4 e 5 edições, respectivamente, demonstrando as dificuldades encontradas no período de nacionalização do ensino. Houve um aumento no número de páginas do periódico a cada década de sua circulação - 504 páginas na década de 1940, 781 páginas na década de 1950 e 776 páginas na década de 1960 (últimos sete anos de edição) - totalizando 2061 páginas em toda sua história. A última edição do periódico foi publicada em junho de 1966. Posteriormente, passou a circular como encarte de uma página no periódico Mensageiro Luterano.

\section{A Matemática no periódico $O$ Pequeno Luterano durante a década de 1940}

O tema de maior participação no periódico envolvia religião e doutrina, ficando evidente o objetivo a atingir. Os conteúdos de disciplinas seculares que apareceram no periódico complementavam a educação escolar. "Estas disciplinas foram consideradas de conhecimento geral, porém, com certa conotação religiosa, ou seja, mesmo os conteúdos de conhecimento geral, quase sempre vinham acompanhados de elementos religiosos" (Weiduschadt, 2012, p. 259).

Com relação à Matemática presente no Pequeno Luterano, observou-se que os editores apostaram numa estratégia envolvendo uma Matemática mais lúdica, diferente das propostas de ensino apresentadas nas aritméticas da série Ordem e Progresso e da série Concórdia (Kuhn \& Bayer, 2017a), editadas pela IELB para suas escolas paroquiais, na primeira metade do século XX. Weiduschadt (2012) acrescenta que:

De forma lúdica, o conhecimento matemático se dava através de charadas, de brincadeiras e de descoberta de enigmas no intuito de desenvolver o raciocínio lógico. As habilidades concretas e abstratas do aprendizado matemático eram valorizadas, em grande parte, através do cálculo mental em forma de brincadeiras lúdicas e prazerosas. (...) Havia relação dos cálculos com as histórias bíblicas (...). Entre as histórias de conhecimento geral, as curiosidades envolvendo a Matemática são apresentadas de inúmeras maneiras. Algumas ensinam cálculos de jogos de descoberta, outras contam a biografia de matemáticos, o modo como lidaram com o conteúdo. (Weiduschadt, 2012, p. 151-152).

Com o propósito de ilustrar e ampliar a discussão, nos quadros 2 a 12 são apresentados fragmentos publicados no Pequeno Luterano, na década de 1940, e que envolvem Matemática. No Quadro 2, por exemplo, descreve-se o desafio de um quadrado com números:
Quadro 2 - Quadrado de aritmética

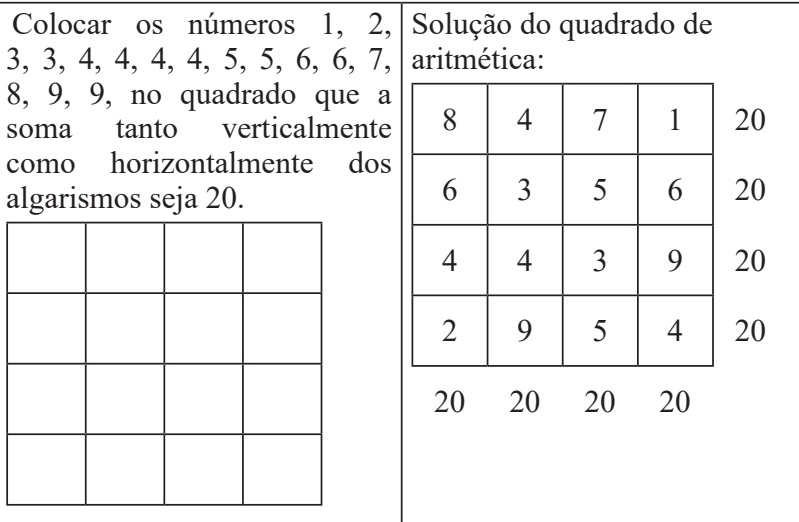

Fonte: O Pequeno Luterano (1939, Fonte: O Pequeno Luterano (1939, ago./set., p.7).

out./nov., p. 16).

O desafio de aritmética, observado no Quadro 2, apresenta 16 números que devem ser distribuídos nos espaços do quadrado de forma que se obtenha a soma 20, na horizontal e na vertical. A solução deste desafio é apresentada na edição posterior do periódico, conforme se pode observar no quadro acima. Ao apresentar a solução do quadrado de aritmética, o editor do periódico escreve: "Certamente devido ao curto tempo não vos foi possível mandar-me algumas soluções. Talvez noutra ocasião" (O Pequeno Luterano, 1939, outubro/ novembro, p. 16). Esta afirmação reforça a estratégia dos editores de receber cartas dos seus leitores, contribuindo para circulação e inserção do periódico entre o público infantil.

Ressalta-se que este quadrado de aritmética desenvolve habilidades para o cálculo escrito e mental, além de apresentar algumas semelhanças com o quadrado mágico. Um quadrado numérico é considerado mágico se ele possui $\mathrm{n}^{2}$ números inteiros positivos e diferentes entre si, tais que, a soma dos $n$ números que figuram nas linhas, colunas, e diagonais, é sempre a mesma. Essa soma comum é chamada constante mágica. Embora, o quadrado descrito no Quadro 2 tenha a mesma soma nas linhas horizontais e verticais, ele não é um quadrado mágico, pois os números 3, 4, 5, 6 e 9 estão repetidos e a soma dos números de cada diagonal não é 20. Complementase que "um dos primeiros registros de um quadrado mágico apareceu na China. Conta a lenda que o quadrado foi trazido aos homens por uma tartaruga, através do Rio Lo, há mais de 4000 anos" (Carvalho, 1997, p. 58).

Além de desafios matemáticos, o periódico traz histórias de cunho moral associadas com conhecimentos matemáticos. A história descrita no Quadro 3, por exemplo, envolve a operação de adição numa fatura: 
Quadro 3 - A história das duas faturas

Um menino ouviu uma noite os pais falar de algumas contas, que era preciso pagar no dia seguinte.

Ocorreu-lhe, então, a ideia de apresentar também a nota dos serviços que entendia haver prestado à sua mãe.

Pela manhã, à hora do almoço, a mãe achou com surpresa debaixo do prato esta fatura:

"Mamãe deve ao seu filho Jorge:

Por ter ido ver quem bate à porta ............................ $1 \$ 000$

Por ter ido ao açougue buscar o peso da carne ........... $2 \$ 400$

Por ter posto o lixo na rua ...................................... $1 \$ 600$

Soma …........................................................ $5 \$ 000$

A mãe guardou a fatura sem dizer nada.

A noite, à hora da ceia, Jorge encontrou, por sua vez, debaixo do prato a conta de cedo mais a importância, uma nota de $5 \$ 000$ novinha em folha.

Muito satisfeito, embolsa o dinheiro.

Dá, porém, sob a sua fatura, com outra que estava regida nestes termos:

"Jorge deve a mamãe:

Pelos cuidados e dores que tem sofrido por sua causa . Nada.

Pelo leite de seus peitos com que o amamentou e criou . Nada.

Pelas noites em claro que passou à sua cabeceira ...........Nada.

Soma ................................................................. Nada."

Quando Jorge leu essa fatura não menos surpreendente, ficou muito envergonhado.

Desfeito em pranto, os lábios trêmulos, corre para a mãe, atira-se-lhe aos braços e, restituindo-lhe o dinheiro, diz:

"Querida mãezinha, peço-lhe que me perdoe. A senhora não deve nada ao seu filho. Sei que não poderei pagar nunca tudo quanto lhe devo. De hoje em diante, farei o que a senhora quiser sem pensar em nenhuma recompensa."

Fonte: O Pequeno Luterano (1941, ago., p.30-31).

A história, descrita no Quadro 3, apresenta a fatura dos serviços prestados pelo filho a sua mãe e a fatura dos serviços prestados pela mãe ao seu filho, finalizando com uma lição de cunho moral, o que evidencia a preocupação dos editores em difundir os princípios morais e educacionais, idealizados pela IELB, entre o público infantil. Ainda de acordo com Rambo (1994), a família como núcleo social embrionário, representava para a criança o palco sobre o qual iria desenvolver as suas primeiras experiências de relacionamento social. Caso fosse bem-sucedida, resultaria uma personalidade equilibrada, segura e positivamente bem integrada.

No Quadro 4, apresenta-se uma lição útil para a vida, contextualizada com a operação de multiplicação:

Quadro 4 - Uma lição útil para a vida

Não há nada que o homem esqueça tão facilmente na vida, como a conta de multiplicar, ainda mesmo que ao sair da escola a saiba com perfeição. E todavia o que na escola se ensina é para servir na vida: a sabedoria não consiste unicamente em saber, mas no bom uso que dela se faz.

Gasta um homem inultimente por dia apenas um tostão. Quem tem muito, pensa que não é grande coisa. Mas no fim de um ano são 365 tostões, e no fim de trinta anos 10.950 tostões, o que perfaz a soma de $1.095 \$ 000$; e isto é muito.

Outro consome na ociosidade duas horas por dia, e entende que não há motivo para ser incriminado. Ao cabo dum ano, porém, são 730 horas, e no fim de trinta anos 21.900 horas, ou sejam 912 dias e meio; dias perdidos da curta vida humana.

A terra tem de circunferência 8 mil léguas de 5 quilômetros. Na realidade é um caminho muito longo. Mas se fosse possível percorrê-lo em linha reta, e houvesse alguém que empregaria para isso só uma hora por dia, caminhando uma légua por hora, decorridos trinta anos, poderia estar de volta em sua casa.

Daqui se vê quanto pode conseguir o homem que apenas emprega uma hora por dia em um negócio útil. Quanto mais poderá conseguir ainda, aproveitando todos os dias para promover o seu próprio bem, o da sua família e o do seu próximo. Quem, todavia, não começa, não acaba também, e aquele a quem o pouco não basta, jamais chegará a saber como do pouco se vai ao muito.

Fonte: O Pequeno Luterano (1941, set., p.35-36).

Na história descrita no Quadro 4, o editor escreve que o homem esquece com facilidade as contas de multiplicar mesmo que as saiba com perfeição ao sair da escola. Acrescenta que a sabedoria não consiste somente em saber, mas no bom uso que se faz dela. Segue dando exemplos de situações de vida das pessoas e finaliza incentivando o aproveitamento do tempo na promoção do seu próprio bem, da família e do próximo. Nesta história de cunho moral, o editor relaciona a operação de multiplicação com o sistema monetário ${ }^{12}$, com unidades de medida de tempo (horas, dias e anos), com unidades de medida de comprimento (léguas e quilômetros) ${ }^{13}$. O editor também faz referência a elementos geométricos, como a circunferência da terra (comprimento) e percurso em linha reta.

Outra história que evidencia os princípios morais e educacionais da IELB e se relaciona com a Matemática, intitulada aritmética cristã, é apresentada no Quadro 5: 
Quadro 5 - A aritmética cristã

Carlinhos fechou o seu livro de aritmética e suspirou aliviado: "Afinal eu terminei!"

Seu pai interrompeu a leitura do jornal e perguntou:

"O que é que terminaste, meu filho?"

"Os meus exercícios de aritmética. Consegui resolver todos eles."

"Tens certeza que estão todos certos?", indagou o pai.

"Naturalmente! A aritmética é facil para mim," respondeu Carlinhos, cheio de satisfação.

"Alegro-me muito com isto. A propósito, que está fazendo a tua aritmética de cristão?"

Surpreso, Carlinhos, perguntou: "Que espécie de aritmética é esta, papai?"

O pai pôs de lado o jornal e explicou: "A aritmética do cristão é a seguinte: ele procura sempre levar mais pessoas para Jesus, se esforça para praticar menos pecados, se empenha em multiplicar as suas boas obras e, por fim, faz toda a diligência para dividir o seu dinheiro entre Deus, o próximo e ele mesmo."

Carlinhos sorriu: "Isto é fácil de lembrar, papai."

"Eu espero que também tu, de hoje em diante, vás praticar esta espécie de aritmética", concluiu o pai seriamente.

Fonte: O Pequeno Luterano (1949, junho, p. 22).

Na história descrita no Quadro 5, o editor emprega os termos da aritmética: mais, menos, multiplicar e dividir, para promover uma reflexão sobre atitudes de um bom cristão. Esta estratégia do editor reforça que "o ensino da palavra de Deus, através da Bíblia, ficava em primeiro lugar, e as demais disciplinas não eram menosprezadas, mas complementavam a educação para servir no mundo" (Lemke, 2001, p. 80).

Os editores do Pequeno Luterano se valiam da estratégia de propor uma Matemática mais lúdica para o seu público leitor, através de charadas e enigmas, conforme se pode observar no Quadro 6:

Quadro 6- Charadas e enigmas

\begin{tabular}{|c|c|}
\hline & Respostas \\
\hline $\begin{array}{l}\text { 1) Um lavrador tem } 4 \frac{1}{2} \text { montões de alfafa num canto da roça e } 5 \frac{1}{4} \text { montões num outro da sua } \\
\text { roça. Se ele os põe todos juntos, quantos montões terá? } \\
\text { 2) Há } 6 \text { maçãs numa cesta e seis pessoas no quarto. Como poderias dar uma maçã a cada uma } \\
\text { e uma maçã ficar na cesta? } \\
\text { 3) Poderás, em } 10 \text { segundos dar } 3 \text { números que dão o mesmo total, somando ou multiplicando? } \\
\text { (1941, novembro, p. 44). }\end{array}$ & $\begin{array}{l}\text { 1) Ele terá um grande montão. } \\
\text { 2) Uma pessoa ganha a cesta com a } \\
\text { maçã. } \\
\text { 3) Os números são } 1,2 \text { e } 3 \text {, pois } 1+ \\
2+3=6 \text { e } 1 \text { × } 2 \text { × } 3=6 \text {. (1941, } \\
\text { novembro, p. } 44) \text {. }\end{array}$ \\
\hline
\end{tabular}

4) Dois pais e dois filhos foram pescar e pegaram três peixes. E cada um levou para casa um peixe. Como foi isso?

5) Se um madeireiro cobrar Cr\$ 3,00 para cortar em dois um tronco de árvore, quanto deve cobrar para cortá-lo em quatro? (1943, março/abril, p. 16).

4) Os pescadores eram o avô, o seu filho e o neto; dois pais e dois filhos, em três pessoas apenas.

5) $\mathrm{Cr} \$ 9,00$, pois para cortar um tronco em quatro pedaços são necessários três cortes. (1943, maio, p. 20).

6) Como se faz a seguinte subtração: O minuendo é 20, o subtraendo 88 e o resto 22 ?

6) XX minuendo

88 subtraendo

7) Como podem restar 10, tirando 1 de 9 ?

22 resto.

8) Uma sala tem 4 cantos; em cada canto há um gato; cada gato vê 3 gatos. Quantos gatos estão na sala? (1943, maio, p. 20).

7) Do número romano IX (9), tira-se I

(1) da frente, fica $X(10)$.

8) 4 gatos. (1943, junho, p. 28).

9) $\mathrm{O}$ avozinho deu uma festa para a qual convidou 20 crianças. O bom do velhinho queria dar, no fim da festa, um canário a cada uma, mas foram-lhe dizer que muitos tinham fugido. Mandou o avô um criado buscar outros para substituir os fugitivos, dizendo-lhe: "Traze uma vez e meia tantos quantos ficaram na gaiola, e mais dois canários e meio." Quando o criado voltou com os canários havia de novo vinte. Quantos haviam fugido?

10) Tirando duma palavra 4 letras, restam oito. Qual é a palavra? (1944, maio, p. 24).

11) Como é que de quatro posso tirar 1 e deixar cinco?

12) Que acontece ao cavalo quando completa sete anos? (1949, junho, p. 24).

9) 13 canários.

10) Biscoito (tira-se bisc).

11) Do número romano IV (4), tira-se I

(1) da frente, fica V (5).

12) Entra no oitavo ano. (1949, julho/ agosto, p. 32).

13) Quantas viagens fará um canoeiro para passar 10 pessoas à outra margem de um rio, 13) 5 viagens, pois em cada viagem numa canoa em que só podem ir 3? (1947, junho, p. 24). vão o canoeiro e mais 2 pessoas.

Fonte: O Pequeno Luterano (1941-1949).

Os editores do Pequeno Luterano também apresentam charadas, enigmas e desafios relacionados com outras áreas do conhecimento. $\mathrm{O}$ foco das charadas e dos enigmas apresentados no Quadro 6 é desenvolver o pensamento lógico das crianças e explorar conhecimentos matemáticos envolvendo as quatro operações elementares com números naturais e a numeração romana. A charada 9 do Quadro 6 também pode ser resolvida por meio de uma equação do $1^{\circ}$ grau com uma incógnita. Chamando de c o número de canários que permaneceram na gaiola, pode-se escrever e resolver a seguinte equação: 


$$
\begin{aligned}
& c+1 \frac{1}{2} c+2 \frac{1}{2}=20 \\
& c+\frac{3}{2} c+\frac{5}{2}=20 / \cdot 2 \\
& 2 c+3 c+5=40 \\
& 5 c+5-5=40-5 \\
& 5 c=35 / \cdot \frac{1}{5}
\end{aligned}
$$

Portanto, 7 canários ficaram na gaiola e 13 canários fugiram, totalizando os 20 canários.

O conhecimento matemático ainda é explorado através de curiosidades numéricas envolvendo as operações de adição, subtração, multiplicação e divisão, conforme se observa no Quadro 7:

Quadro 7 - Curiosidades numéricas

1) $123456789 \times \quad 9+10=1111111111$

$123456789 \times 18+20=2222222222$

$123456789 \times 27+30=3333333333$

$123456789 \times 36+40=4444444444$

$123456789 \times 45+50=5555555555$

$123456789 \times 54+60=6666666666$

$123456789 \times 63+70=7777777777$

$123456789 \times 72+80=8888888888$

$123456789 \times 81+90=9999999999$

A tabela ainda fica mais interessante, quando se sabe que os fatores são divisíveis por 9; e que a soma de cada soma-produto (os algarismos dele) menos a parcela, tem como resto 0. Por exemplo: a soma de 3333333333 menos 30 igual a zero.

Fonte: O Pequeno Luterano (1943, setembro, p. 36).

Os excertos apresentados no Quadro 7 trazem curiosidades numéricas. A primeira envolve o produto do número 123456789 pelos múltiplos de 9 , compreendidos entre 9 e 81 , somados, respectivamente, aos múltiplos de 10 , compreendidos entre 10 e 90 , resultando sempre em número com dez algarismos repetidos. O editor complementa esta curiosidade com observações sobre a mesma, instigando os leitores a fazer as verificações. A segunda curiosidade numérica traz os produtos
2) $987654321 \times 9=8888888889$

$987654321 \times 18=17777777778$

$987654321 \times 27=26666666667$

$987654321 \times 36=35555555556$

$987654321 \times 45=44444444445$

$987654321 \times 54=53333333334$

\begin{tabular}{|c|c|}
\hline $\begin{array}{l}\text { 1) Escreve-se um número de três algarismos, por } \\
\text { qualquer outro exemplo prova, pode ser dividi }\end{array}$ & etido, assim que dê o número 365365 de seis algarismos, que, como \\
\hline 2) & 3) \\
\hline $1 \times 9+2=11$ & $1 \times 8+1=9$ \\
\hline $12 \times 9+3=111$ & $12 \times 8+2=98$ \\
\hline $123 \times 9+4=1111$ & $123 \times 8+3=987$ \\
\hline $1234 \times 9+5=11111$ & $1234 \times 8+4=9876$ \\
\hline $12345 \times 9+6=111111$ & $12345 \times 8+5=98765$ \\
\hline $123456 \times 9+7=1111111$ & $123456 \times 8+6=987654$ \\
\hline $1234567 \times 9+8=11111111$ & $1234567 \times 8+7=9876543$ \\
\hline $12345678 \times 9+9=111111111$ & $12345678 \times 8+8=98765432$ \\
\hline & $123456789 \times 8+9=987654321$ \\
\hline
\end{tabular}

$987654321 \times 63=62222222223$

$987654321 \times 72=71111111112$

$987654321 \times 81=80000000001$

Quadro 8 - Outras curiosidades numéricas

Fonte: O Pequeno Luterano (1945, novembro/dezembro, p. 48).

O Quadro 8 traz mais três curiosidades numéricas encontradas no periódico. A primeira, parte de números com três algarismos, repete-os igualmente, resultando em um número com seis algarismos e divisível por 7, 11 e 13. Esta explicação é exemplificada com o número 365 . A mesma é válida para qualquer outro número com três algarismos, pois $7 \times 11 \times 13=1001$ e multiplicando-se um número de três algarismos por 1001, obtém-se um número com seis algarismos, havendo a repetição dos algarismos do número da multiplicação do número 987654321 pelos múltiplos de 9, compreendidos ente 9 e 81 . Observa-se que o primeiro e o último algarismos de cada produto, são, respectivamente, o algarismo da dezena e da unidade de cada múltiplo de 9 multiplicado, e os demais algarismos são iguais e uma unidade a menos que o algarismo das unidades do referido múltiplo de 9.

No Quadro 8 se apresentam outras curiosidades numéricas encontradas no Pequeno Luterano: inicial, na mesma ordem. No caso do exemplo apresentado pelo editor do periódico, 365 x $1001=365365$. A afirmação também é valida para números com três algarismos, sendo dois ou os três repetidos. Por exemplo:

a) $202 \times 1001=202202$ que é divisível por 7, 11 e 13 .

b) 999 x 1001 = 999999 que também é divisível por 7, 11 e 13 .

A segunda curiosidade apresenta oito resultados interessantes, a partir de multiplicações por 9 e somas de 2 a 9 , 
sendo que os resultados são números com todos os algarismos iguais a 1. Observa-se que a quantidade de algarismos 1 coincide com a parcela que é adicionada a cada produto, sendo que o aumento gradativo do número de algarismos do resultado está relacionado ao aumento de um algarismo, em ordem crescente ( 2 a 8), no primeiro fator das multiplicações.

$\mathrm{Na}$ terceira curiosidade numérica se observam nove multiplicações por 8 e somas crescentes de 1 a 9 , sendo que a quantidade de algarismos do resultado de cada cálculo é igual a parcela que está sendo adicionada ao produto. Verifica- se também que há o aumento de um algarismo, em ordem crescente (2 a 9), no primeiro fator das multiplicações e o aumento de um algarismo, em ordem decrescente ( 8 a 1), nos resultados finais.

Com essas curiosidades numéricas os editores buscavam despertar o interesse e a curiosidade das crianças, contribuindo para a circulação do periódico pelas comunidades em que as escolas paroquiais luteranas gaúchas estavam inseridas.

No Quadro 9 se apresenta uma habilidade Matemática que pode ser realizada com um livro, segundo o editor do periódico:

Quadro 9 - Uma habilidade que se faz com um livro

Esta habilidade é realmente espantosa, até um sábio que a não conheça poderá ficar atrapalhado, sem poder compreender como se fazem as cousas.

Convida-se uma pessoa, de preferência a mais ilustrada, a tirar da estante qualquer livro que deseje; deve abri-lo ao acaso e escolher uma palavra nas primeiras nove linhas da página que tiver a sua frente; toma em seguida nota do número da página e multiplica-o por 10; ao produto junta 25 e o número da linha em que está a palavra que escolheu.

O resultado assim obtido volta a ser multiplicado por 10, juntando-se ao produto o número de ordem da palavra na linha.

Entrega-nos então o livro e um pedaço de papel onde está escrito o número obtido, mas sem as operações donde resultou, e depois de alguns momentos de reflexão conseguiremos abrir o livro e encontrar a palavra escolhida.

Para obtermos este espantoso resultado, basta apenas subtrair mentalmente 250 do número que vinha escrito no papel. O último algarismo é o número da palavra, o penúltimo o da linha, e os restantes o da página.

Suponhamos, por exemplo, que a palavra escolhida era a $5^{\text {a }}$ e estava na $9^{a}$ linha da página 100 . Neste caso a operação era a seguinte:

$100 \times 10=1000$

$1000+25+9=1034$

$1034 \times 10=10340$

$10340+5=10345$

Era este número, 1034, que nos era dado, e 5 é o que basta realmente para encontrar o número da página, da linha e da palavra, pois que, subtraindo 250 de 10345 vem:

$10345-250=10095$

O número 10095, dividido exatamente como se explicou, dá-nos 100,9, 5, sendo estas as três parcelas necessárias para descobrir a palavra.

Fonte: O Pequeno Luterano (1944, maio, p. 19).

No excerto, apresentado no Quadro 9, o editor explora uma habilidade Matemática com um livro, a qual exige atenção dos desafiados para fazerem corretamente os cálculos que envolvem as operações de adição, subtração e multiplicação e, então, poderem encontrar a palavra escolhida inicalmente no livro. A curiosidade explora a habilidade de resolução de uma expressão numérica. Observa-se que, de forma lúdica, são desenvolvidas habilidades para o cálculo mental e escrito com os envolvidos na brincadeira.

O periódico apresenta ainda um processo expedito de multiplicar onze, conforme descrito no Quadro 10:

Quadro 10 - Processo expedito de multiplicar por onze

Suponhamos que queremos multiplicar 45 por 11. Somamos os dois algarismos que formam o número e escrevemos a soma no meio deles. O produto é 495 . Se se tratasse de 75 , como a soma dava 12, escrevia-se 2 no meio, e somava-se 1 com o algarismo das dezenas: 825. Quando o número tem muitos algarismos, aplica-se no fundo a mesma regra, escrevendo os dois algarismos extremos, e somando cada algarismo com o que está escrito na casa à esquerda. Assim, 1545 multiplicado por 11 dá 16995.

Fonte: O Pequeno Luterano (1944, novembro, p. 48).
O fragmento do periódico apresentado no Quadro 10, descreve um processo prático de fazer multiplicações por 11, explicando o procedimento por meio de três exemplos. Para se chegar ao resultado do último exemplo do editor, 1545 x 11, é preciso realizar o seguinte procedimento: escrevem-se os dois algarismos extremos, 1 e 5, somam-se os dois algarismos da esquerda do número $(1+5=6)$, os dois algarismos do meio $(5+4=9)$ e os dois algarismos da direita do número $(4+5=$ 9). As somas são escritas entre os extremos 1 e 5 , na ordem em que as somas foram descritas, ou seja:

$$
\overbrace{69}^{9} \times 11=16995
$$

É importante lembrar que, no caso da soma resultar em uma dezena ou mais, o algarismo da dezena é somado com o algarismo escrito imediamente a esquerda da posição que o algarismo da soma deve ocupar no resultado, como no seguinte exemplo:

$$
\overbrace{}^{81 \times 8} 8^{(+1)} \times 11=67958
$$


Ao multiplicar um número com três algarismos por 11, escrevem-se os dois algarismos extremos, somam-se os dois algarismos da esquerda do número e os dois algarismos da direita do número. Estas somas são escritas entre os extremos, na ordem em que foram realizadas, isto é:

$832 \times 11=9152$, o algarismo 1 da dezena da $1^{\text {a }}$ soma é 115 somado ao extremo 8 .
O processo expedito de multiplicar por 11 evidencia, novamente, a preocupação dos editores do periódico em contribuir com seus leitores para o desenvolvimento de habilidades para o cálculo escrito e mental.

No Quadro 11, apresenta-se uma curiosidade envolvendo o número 40 e a Bíblia, localizado no Pequeno Luterano:

Quadro 11 - O número 40 e a Bíblia

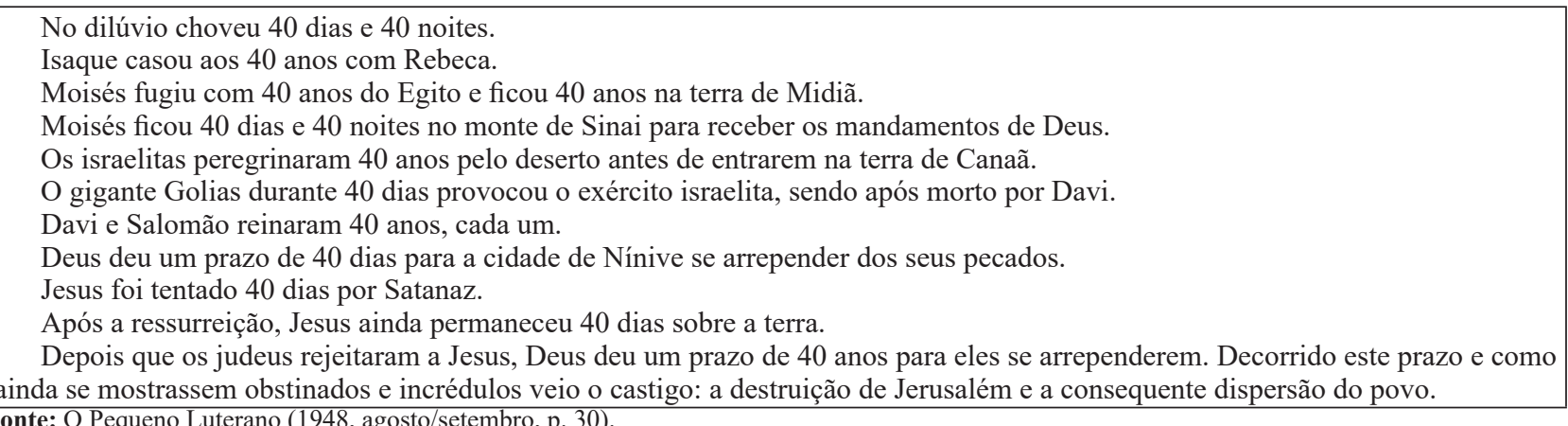
Fonte: O Pequeno Luterano (1948, agosto/setembro, p. 30).

A curiosidade descrita no Quadro 11 relaciona o número 40 com passagens bíblicas. Este fragmento evidencia a preocupação do Sínodo de Missouri, através dos editores do Pequeno Luterano, em manter um ensino sistematizado aos seus fiéis, sendo necessário consolidar um campo religioso e fortalecê-lo investindo na escola e no campo familiar dos seus possíveis fiéis (Weiduschadt, 2012).

No Pequeno Luterano também foi localizado um fragmento que fala sobre o matemático Gauss ${ }^{14}$, conforme descrito no Quadro 12:

Quadro 12 - O grande matemático Gauss

O grande matemático alemão Carlos Frederico Gauss (falecido em 1855), deu já na idade de 7 anos provas de sua grande inteligência. Um dia, o professor escreveu no quadro-negro o seguinte exercício: "Calculem a soma de todos os números de 1 até 100". As crianças puseram-se a somar diligentemente, enquanto o jovem Gauss, ao fim de alguns segundos, exclamou: "Pronto!". O professor chamou-o para ver a resposta. Ficou atônito ao ver a solução certa. Como era possível, fazer isto em alguns segundos?

Gauss notara que os números de 1 a 100 podiam ser agrupados dois a dois, na ordem crescente de um e decrescente do outro: 1 e 100, 2 e 99, 3 e 98, 4 e 97, 5 e 96, etc., e que a soma dessas duas parcelas era sempre igual a 101.

Como havia 50 grupos assim, o problema se reduzia a uma simples multiplicação:

$50 \times 101=5050$.

Fonte: O Pequeno Luterano (1949, maio, pp. 19-20).

Com o título $O$ grande matemático, o periódico conta como Gauss chegou rapidamente à soma dos números de 1 a 100, quando tinha 7 anos. Gauss observou que a soma de dois termos equidistantes dos extremos era igual à soma dos extremos, ou seja, 101, a qual foi multiplicada pelas 50 parcelas obtidas, resultando em 5050. Este procedimento originou, posteriormente, a fórmula para determinação da soma dos termos de uma progressão aritmética ${ }^{15}$ (PA) finita. No exemplo de Gauss, pretende-se obter a soma dos termos da PA finita (1, $2,3, \ldots, 100)$, em que o primeiro termo é 1 , o último termo é 100, o número de termos é 100 e a razão é 1 . Logo, tem-se:

A soma dos termos de uma PA finita pode ser determinada por:

$\begin{array}{ll}\mathrm{a}_{1}=1 & \mathrm{~S}_{\mathrm{n}}=\frac{\left(\mathrm{a}_{1}+\mathrm{a}_{\mathrm{n}}\right) \cdot \mathrm{n}}{2} \\ \mathrm{a}_{\mathrm{n}}=100 & \mathrm{~S}_{\mathrm{n}}=\frac{(1+100) \cdot 100}{2} \\ \mathrm{n}=100 & \mathrm{~S}_{\mathrm{n}}=\frac{101 \cdot 100}{2} \\ \mathrm{r}=1 & \mathrm{~S}_{\mathrm{n}}=101 \cdot 50 \\ \mathrm{~S}_{\mathrm{n}}=? & \mathrm{~S}_{\mathrm{n}}=5050\end{array}$

E assim, de uma forma lúdica, os editores do periódico permitiam, ao público leitor, o contato com conhecimentos matemáticos, para o desenvolvimento do raciocínio lógico e de habilidades para o cálculo escrito e mental.

\footnotetext{
14 Johann Carl Friedrich Gauss (1777-1855) foi matemático, astrônomo, físico e contribuiu em diversas áreas da ciência, dentre elas a teoria dos números, estatística, análise matemática, geometria diferencial, geofísica, astronomia e óptica. Gauss considerava a Matemática como a rainha das ciências.

15 Progressão Aritmética é toda sequência de números na qual a diferença entre cada termo (a partir do segundo) e o termo anterior é constante. Essa diferença constante é chamada razão (r) da progressão aritmética.
} 


\section{Conclusão}

Como as escolas paroquiais luteranas gaúchas do século XX estavam inseridas num projeto missionário e comunitário que buscava ensinar a língua materna, a Matemática, valores culturais, sociais e, principalmente, religiosos, a IELB se preocupou em produzir materiais pedagógicos para suas escolas. Através da Casa Publicadora Concórdia, de Porto Alegre, a IELB editou e publicou livros didáticos e periódicos, como o periódico O Pequeno Luterano, de acordo com seus princípios morais e educacionais. Além de educarem e doutrinarem pela palavra de Deus, os periódicos editados pela Igreja Luterana se direcionavam para o ensino das crianças nas escolas paroquiais, trazendo artigos com orientações didáticas e informações sobre conteúdos formais.

O Pequeno Luterano teve 217 edições (mensais/ bimestrais/quadrimestrais), no período de agosto/setembro de 1939 a junho de 1966, quando passou a circular como encarte de uma página no periódico Mensageiro Luterano. O principal objetivo dos editores do periódico era, de forma lúdica, inserir as crianças na prática religiosa luterana por meio de textos, histórias, informações e curiosidades de cunho moral e religioso e de formação geral. Dessa forma, foi usado pelos professores paroquiais, complementarmente, no ensino das diferentes áreas do conhecimento nas escolas paroquiais luteranas gaúchas do século passado.

Fundamentando-se no referencial teórico-metodológico da pesquisa histórica e do conceito de cultura escolar, investigouse a Matemática presente no Pequeno Luterano, durante a década de 1940. O conteúdo lúdico e outros similares foram usados pelos editores como estratégia do periódico para atrair a atenção das crianças. Contudo, ao mesmo tempo, em que tais publicações envolviam curiosidades e desafios, continham elementos doutrinários, principalmente de aprendizado da Bíblia e da vida de Lutero.

Constatou-se que os editores propunham desafios matemáticos para desenvolver o raciocínio lógico das crianças e valorizavam as habilidades concretas e abstratas do aprendizado matemático através do cálculo escrito e mental, em forma de atividades lúdicas e prazerosas. Cálculos foram relacionados com a biografia de matemáticos e os conhecimentos matemáticos integrados a histórias de cunho moral e religioso, com o propósito de manter as crianças inseridas na prática religiosa luterana. Curiosidades e desafios matemáticos semelhantes aos localizados no Pequeno
Luterano, também estão presentes nos livros de Matemática atuais e em publicações, como as de Malba Tahan.

\section{Referências}

Carvalho, M. C. C. S. (1997). Padrões numéricos e sequências. São Paulo: Moderna.

Certeau, M. (1982). A escrita da História. Rio de Janeiro: Forense Universitária.

Chervel, A. (1990). História das disciplinas escolares - reflexões sobre um campo de pesquisa. Teoria \& Educação, (2), 177 229.

Julia, D. (2001, Janeiro/junho). A cultura escolar como objeto histórico. Revista Brasileira de História da Educação, (1), 9-43.

Kuhn, M. C., \& Bayer, A. (2017a). A matemática nas escolas paroquiais luteranas gaúchas do século $X X$. Canoas: Ed. ULBRA.

Kuhn, M. C., \& Bayer, A. (2017b). O contexto histórico das escolas paroquiais luteranas gaúchas do século XX. Canoas: Ed. ULBRA.

Lemke, M. D. (2001). Os princípios da educação cristã luterana e a gestão de escolas confessionárias no contexto das ideias pedagógicas no sul do Brasil (1824 - 1997). Canoas: Ed. ULBRA.

O Pequeno Luterano. (1939-1966). Porto Alegre: Casa Publicadora Concórdia.

Prost, A. (2008). Doze lições sobre a História. Belo Horizonte: Autêntica.

Rambo, A. B. (1994). A escola comunitária teuto-brasileira católica. São Leopoldo: Ed. UNISINOS.

Série Concórdia: Terceira Aritmética. (1949). Porto Alegre: Casa Publicadora Concórdia.

Valente, W. R. (2007). História da Educação Matemática: interrogações metodológicas. REVEMAT-Revista Eletrônica de Educação Matemática, 2.2, 28-49.

Warth, C. H. (1979). Crônicas da Igreja: Fatos Históricos da Igreja Evangélica Luterana do Brasil (1900 a 1974). Porto Alegre: Concórdia.

Weiduschadt, P. (2012). A revista "O Pequeno Luterano" e a formação educativa religiosa luterana no contexto pomerano em Pelotas - RS (1931-1966) (Tese de Doutoramento). Universidade do Vale do Rio dos Sinos, São Leopoldo.

Weiduschadt, P. (2007). O Sínodo de Missouri e a educação pomerana em Pelotas e São Lourenço do Sul nas primeiras décadas do século $X X$ : identidade e cultura escolar (Dissertação de Mestrado). Universidade Federal de Pelotas, Pelotas. 